\title{
Webinar Transcript:
}

\section{Supporting Emotion Regulation in Early Childhood}

\section{August 30, 2018}

DAVID YANOSKI: So today's webinar is brought to you by REL Central and the title is, "Supporting Emotion Regulation in Early Childhood." Our presenter today is Crystal Day-Hess. And Crystal is the Assistant Director at the Marsico Institute for Early Learning and Literacy at the University of Denver where she conducts early childhood research and provides professional development trainings across the country. Dr. Day-Hess has extensive experience developing, coordinating, and conducting research in the early childhood field, focusing on children's cognitive, social, and emotional school readiness skills such as self-regulation over executive function, play, achievement motivation, and caregiver sensitivity. In addition, she has experience developing, coordinating, and conducting professional development workshops for early childhood educators and administrators in multiple context and settings.

And so we are excited-we are excited to bring Dr. Day-Hess here to speak for us today. So Crystal, if you could go ahead and take it away.

CRYSTAL DAY-HESS: Thank you David-so thank you everyone for joining us today. I wanted to talk briefly about our goals for today. So, we will be reviewing this practice guide from the What Works Clearinghouse. And as part of this, we're going to be talking a lot about today-what is emotion regulation and how does it play a role in behavior regulation in the early childhood classroom?

We'll also focus on two of the five Recommendations that are the focus of this practice guide and look at those in a little more detail and talk about some hands on things that you can try in your classroom, if you're not already. And finally, we will actually see and watch some examples of these practical strategies that hopefully you can give a try in your classroom.

So, here is the link to the practice guide. So if you-and just Googling it might get you there a little faster. They also have the link posted in the chat box. Thank you, David and team. They just posted that for you as well. Or you can just Google the title here, "Reducing Behavior Problems in the Elementary School Classroom," and you'll get this PDF that you see on your screen here.

So again, this is going to form the basis of our talk today. And we will keep moving forward here as soon as my slides cooperate. There we go.

So here are the five recommendations in the practice guide. So you see Recommendation 1, "Identifying specifics of the problem behavior and the conditions that prompt and reinforce it." 
So this is one of the recommendations. We encourage you to download that guide and read on your own outside of this webinar. We will not be covering that one today to a lot of extent. The other two that we will not cover today, but I want to draw your attention to, are Recommendations 4 and 5. So Recommendation 4 you see is, "Draw on relationships with your colleagues and the families of the children that you work with for continued guidance and support." So really drawing on that support system to understand how you can best support kids in your class that may be having some emotion regulation challenges, for whatever reason. And then finally the last recommendation that we will not touch on today, but I think is important to consider today-and your program may already be doing something like this - is assessing whether school-wide behavior problems might warrant some adopting of school-wide strategies and programs in your setting.

So what we are going to focus on today, again, are Recommendations 2 and 3. So let's take a closer look at-at those.

So Recommendation 2. So first today, we are going to focus on ways that we can modify the classroom learning environment to help decrease problem behavior. So as you all know, there are a lot of different ways that we can do this. There's no magic answer, unfortunately, to any behavior challenges.

As we know there are huge individual differences and sometimes those kiddos just-you never know what they're going to do from one day to the next. So we have to be flexible. But we'll talk about some of these examples today. We know that many effective classroom-focused interventions that decrease students' problematic behavior are a result of interventions that alter or remove factors that trigger them. So we want to figure out, what are the triggers? And if we can, let's alter them or remove them if possible. And we know these triggers can be a mismatch between the classroom setting or maybe the academic demands and what the student's strengths are, or even their preferences and skills.

So some ways that we can reduce the occurrence of some of these inappropriate behaviors, that we'll talk about today, are revisiting and reinforcing classroom behavioral expectations. We'll also talk about ways you might be able to rearrange or arrange the classroom environment. We'll look at scheduling and some ways that we can present schedules to kids to hopefully eliminate or at least reduce some of those challenges that may revolve around that. We'll also talk about some learning activities to meet students' needs, so some ways you might be able to set up and structure those. And then finally, we'll touch a little bit on individual adapting instruction to promote student engagement in on-task behavior. You all know this and we've all seen it before, when you have those kiddos that are motivated and engaged with what's going on in the classroom, if we see that in kids, they tend to be, for the most, a little less-less likely to display some of these challenging behaviors. 
So the other recommendation we'll touch on today here is Recommendation 3. So we're actually going to look at some specific strategies to teach and reinforce new skills to increase appropriate behavior and really set up a positive classroom environment that can help support those positive behaviors in all kids.

So towards the end of our time together today, we'll look at some great examples from the developers of The Pyramid Model. So, some actual activities that are explicitly designed to teach social skills and emotional skills. So we'll touch on those today and look at a couple examples a little bit later.

So let's jump in. Let's get started.

So in the Q\&A box that you have on your screen, we want you to take a few minutes and type in some responses here. What are some of the challenges that you have observed with students or children in your classrooms in relation to emotion regulation? So take a few minutes. We will stop talking. If you have others with you as you're watching this webinar, please feel free to chat with them as well and put some of your responses, again, in that Q\&A box.

Okay. So please, feel free to keep typing your responses in that Q\&A box. But we saw, as you all may have seen as well, you know, a number of you mentioned physical aggression or hostile behaviors, um, potentially just being overstimulated or impulsive behavior-kids who may be more reactive to their feelings and perhaps it's because - I think you all helped identify why that may be happening-perhaps it's because they can't identify their emotions or maybe they don't have the skills - a skill set that will allow them to figure out how to address - maybe they do know that they're angry, but they just don't know what to do with that. Or maybe they're upset that their friend or a kid in the classroom won't share a toy with them but they don't know, what are my acceptable option. So those are some things we'll actually talk about a little bit later in this webinar. Also we saw a lot of kids that essentially-you were saying they can't de-escalate. Once they get really worked up, they don't know what to do and they lash out. And in a bit, we'll actually watch a video and look at an activity that is, Tucker the Turtle. So it's a book and you can get cute little puppets to go along with it as well. But a nice little technique that can help kids kind of tuck into their shell, take deep breaths, and kind of give them these series of several steps that they can go through to help them take a moment and think about what-you know, I'm upset. Instead of immediately acting out, my reaction's going to be to go into my shell and think about why I am upset, as opposed to initially reacting. So we'll look at some of those as well.

Um, I also saw something in there about unexpected changes in routine, so we'll talk a little bit about ways that we might be able to mark and give kids as much of a head's up as possible that changes in schedules or routines are going to be happening. So great. Thank you for sharing. 
And like I said, we will-we will touch on a lot of these as we're going through some activities today.

But before we do that, I want to take just a minute and make sure we're all on the same page. A little overview or never or reminder never hurts. When we say emotion regulation, what are we talking about? Why does it matter? What are we thinking about here?

So in terms of what can be regulated, right? We know that in order to address challenging behaviors, we need to know where it begins, which a lot you were identifying some of these things in your comments here. While we know that there are definitely certain triggers that may initiate problem behaviors, we often-right, if we have the time and are perceptive enough-we can often trace back-trace those challenges back even further to figure out what's going on. And a lot of times, it is an emotion regulation issue. Or it can also be a cognitive or physical regulation issue. So briefly, physical regulation is kids' ability to physically control themselves in a situation. So this might be something as simple as not running out into the street when they want to go chase the ball that went out to the street. Or as you all were noting, I'm really, really frustrated, but my initial physical reaction may be to lash out-throw something or hit the person that made me upset. And sometimes that really can be a physical regulation issue in combination with perhaps the cognitive or emotional regulation issue.

We also-again, our big focus today is emotion regulation. So these are those kiddos that, for a variety of reasons, they get upset and they just - their initial reaction is what comes out of them. Right? They just don't quite have the ability to regulate those emotions yet. And as you all have pointed out and what actually was in Recommendation 1 of this practice guide are some tips for ways you can help, that can help you think about what is the trigger? What's leading to this physical regulation or emotion regulation issue?

So I encourage you all to download that practice guide and take a look at Recommendation 1 as well to maybe give you some new ideas for tips that maybe you just haven't tried yet for trying to identify those triggers.

And then finally, we have cognitive regulation. So I think this is an interesting one that is likelyyou know, if you're having these challenging behaviors, they're probably emotion regulation issues, but also some cognitive regulation issues happening in there. So cognitive regulation refers to things like kids' ability to attend to tasks. So their attention. It's related to how much and what information we keep in mind. So our working memory. So we know that these young kiddos, they can only hold so much information in their head and juggle that all at one time. And sometimes that just becomes really too much for them to handle and can become overstimulating for them. And that may sometimes be a challenge that's coming into play.

Cognitive regulation is also about our ability to shift our attention in thinking. So um, right? So, thinking, I really, really am paying attention to my friend who has the toy I want. And I can't 
shift my attention away to anything else. So sometimes it's an inability to shift attention from something or to perseverate on something.

What's interesting is that shifting attention also comes into play when we think about our ability to take someone else's perspective. So if kids have a problem with-with not being able to shift their attention or to think of things from another perspective, that sometimes leads them to demonstrate these behaviors that can, from our perspective, can seem very selffocused. And you know, we just want you to think about how your friend is feeling. But sometimes if there is a cognitive regulation issue, or they don't have that cognitive flexibility, they may not be able to do that just yet. So we'll talk about ways we can support them in that as well.

Alright. So let's see here. We're going to think about-again, keep in mind all of these and how they might relate to different social skills that we'll be talking about later. Alright.

So please forgive us here. We're trying to keep the slides moving and answering questions. So forgive us if we have a little bit of a pause here. But we appreciate your patience with us.

Okay, so how do we learn to regulate our behavior? So this is a slide we're going to come back to as a refresher a couple of times throughout this presentation. Our ultimate goal is we want kids to be regulating behaviors on their own.

So in the case of today's webinar and our time together today, we're going to be talking about regulating or controlling emotions and things we can do in the classroom to help support that. Right, this is important because we don't want to teach your adult to constantly have to be telling them not to hit their friend or not to throw things. We don't want this happening at all. But we have to also in some ways be patient, especially those of us that are working with younger kids, preschool age, kindergarten, first grade. We know that these regulation behaviors developed in certain steps.

So first, we start with regulation by others. So this is where teachers or adults are doing a lot of the regulating of kids. So this is where it becomes important to set clear boundaries and rules or behavior expectations for kiddos. So again, first it starts with other people having to regulate the child. Then we move into other regulations, so this is actually an interesting stage where we see kids - they're starting to get an understanding of the rules and the expectations and what they're allowed to do and not do.

But they are in this other regulation stage where they can state the rules for others, but they can't quite follow them themselves yet. So this is kind of like us as adults. We're all probably excellent backseat drivers. I'm the best backseat driver on the planet, I'm pretty sure. But when I get behind the wheel, I might not always follow the rules that I know are the rules. This is an adult example of this other regulation. Another example, what this looks like in kids, is often 
when you have young kids who are doing a lot of tattling on their friends. You know, he's not doing this or she did this. And they are very good at telling you what other kids are doing wrong, but then they might turn around and do it themselves five seconds later. So this is a good sign that you have kids that might be in the other regulation stage where they know the rules, but they're just not able to fully apply them to themselves yet.

And then finally we move into self-regulation. So this is where we see kids really starting to finally apply those rules and expectations to themselves as well. So while we know these develop over time, we also know that it's not a clear cut thing. You're not going to have kids that are always in self-regulation, never go back to other regulation or need to be regulated by others. But I think nonetheless this is a helpful kind of developmental path for us to keep in mind that-especially the young kiddos that we're all working with, they're very much in the middle of all of these different things at any given time. So it might feel like, oh my goodness they were so great at following these rules yesterday and we talked about them 20 times, but here we are two days later and I have to remind them again because now they're back at the bottom here and I have to regulate them, and maybe they know when their friends are breaking the rules, but now they're not following them either. So I think these three things are really helpful to keep in mind, and also may help you keep your sanity as well as you find yourself revisiting rules over and over again.

Alright. So want to do a little game with you all, if you will. So here, we know that selfregulation or emotion regulation is hard. So we know emotion regulation is just one piece of self-regulation. It's a hard skill. We need to nurture this skill in the classroom. But just to give us a sense, to make us even more aware of what the kids might be going through every day in a classroom, um, we're going to play this little game.

So this task that you see here on a screen, this little girl playing was-and it's an executive function or self-regulation task that was developed by a researcher, Adele Diamond. And we actually use this task to assess children's executive function skills. So things like their emotional, physical, cognitive self-regulation. A lot of their cognitive self-regulation comes into play here. And we're actually going to give you a little preview. We're going to have you take the same test that we give to kiddos.

So you see on the picture here is notice how the child uses the left hand to push on the left screen and the right hand to push on the right side of the screen. Now we're going to have you practice this, but obviously you don't have the touch screens, right? So what I want you to do is put your hands on your lap or on the desk in front of you or somewhere so that you can do some tapping here, because I'm going to show you a series of slides and you're going to be asked to do this task as a child would.

Alright. So let's get started. For our first task here, this is our congruent task. So what that means for this first series of slides, have your hands ready on your lap or on the table in front of 
you. Each time you see a heart, tap with your finger on the same side as the heart. So if you see a heart on the left side of the screen, tap with your left finger or left hand. You see a heart on the right side of the screen, tap with your right finger or right hand.

Alright. Ready? Here we go.

Alright. So kids obviously get a lot more trials of this and they go for longer. But pretty easy, right? Pretty straightforward. We're asking you to do a task, this congruent task. So I'm asking you, something is on the left, I want to push on the left. If it's on the right, push on the right. So pretty straightforward. Not a lot of information to keep in mind there. Pretty automatic. Now we're going to make it a little more complicated. So now what I want you to do is when you see a flour-so this round is all flowers-now when we see this flower, I want you to press on the opposite side of the flower. So if you see a flower on the left hand side of your screen, I want you to push with your right hand. And then likewise, if you see a flower on the right hand side of the screen, I want you to push with your left hand or left finger. So you can see, this is going to require you to inhibit your natural tendency to respond on the same side and now we want you to press on the opposite side of the flower.

Alright. Get ready. And here we go.

Alright. So how was that? Right? Probably a little bit harder because now I'm asking you to inhibit your dominant response, which is to do--which is to hit on the same side, and ask you to do the opposite. Alright. So now I am gonna make it even harder. And again, like I said, "kids actually-we give kids some of these tests."

But now we're going to do a mixed. So now it's going to get really, really interesting really quickly here. So now sometimes you'll see a heart and sometimes you're going to see a flower. And I want you to switch between the rules that we just went through. And the rules stay the same. So every time you see a heart, press on the same side. Every time you see a flower, press on the opposite side.

Get ready. And here we go.

So how did you do on that one? Nothing like a little challenging task to get us going here. So if you're like-you know, almost all people, and like my colleague who's with me here today included, I think - that was significantly harder. That was a really hard task. And I have to tell you, we actually had this up on a computer screen. I took it a lot and I didn't - I did good on the first two trials. And once I got to the third where step was mixed, you can forget it. It all went out the window.

So if you think about it, this last task that we did requires all three components of selfregulation simultaneously. So it requires holding two rules in mind-the heart's the same side, 
flowers the opposite side. And then sometimes you have to keep both of those in mind. Sometimes it's here. Sometimes it's there. It's a different stimulus. You have to keep all the rules in your head.

And why this matters is - this is what it can feel like for some kids in the classroom. So especially those who might have a hard time controlling their emotions or might have issues with that physical or cognitive self-regulation, as well. This is what it can feel like in the classroom for these kiddos is, you know, my natural tendency for whatever reason-maybe it's something I've learned in my home environment or some other environment-my-what l've learned is that when you get upset, you throw things, or you hit, or you scream, or you yell. That's my natural tendency. That's what is natural for me, what l've learned, what l've picked up from wherever. But in a classroom, I now have a different rule. I have to do something that's the opposite, or I have to do-I have different rules for different scenarios, kind of like our mixed task where you had hearts and flowers.

So just something to keep in mind. As frustrating and as challenging as this was for you, this can be what it's like for kiddos in the classroom. Especially as you all know, we never know what they're coming to us with sometimes. And we just have to keep in mind that all of these things can be coming into play with these challenging behaviors.

So why does it matter? Well, you know, we know from a lot of research-and you all I'm sure know from your own firsthand experience-that being able to control our emotions is connected to kids' achievement in school. So we actually know from a lot of different studies that emotional regulation leads to benefits in all areas of kids' lives. So kids who can regulate their emotions, as older children they pay closer attention. They work harder. They might achieve more in school. We know that this emotion regulation is key in allowing kids to complete tasks, even when they're dealing with difficult problem-solving, or they're just tired, or they're distracted, or they're just not motivated. Let's be honest-we can't design every single task that's always exciting and motivating for every kid, but kids who have the emotional regulation thing kind of under control are a little bit better equipped to go ahead and stay on task and still work on those activities anyway.

And not surprising to you all, I'm sure, we have a lot of kindergarten teachers on our call today and in a study of kindergarten teachers, they actually found that those teachers say that regulatory processes - so these things about self-regulation, emotion regulation-are just as important to them as having kids who come in knowing their letters and numbers. And in fact, a lot of teachers said that it might be even more important to them or even more helpful if kids have these skills as well. And then on the converse, we know that these lack of emotion regulation skills are related to poor social skills-aggression, which a lot of you mentioned those in your examples that you're providing for us earlier. These kiddos are also at risk for higher rates of disciplinary problems early in school, but also later on, and later throughout their entire lives. We know that these emotion regulation issues create difficulties for them in 
cooperating and resolving conflicts successfully. So whether that's with adults or with kids their own age, with their peers. And what's interesting-and you all have probably experienced this as well because for all humans, sometimes when you have those kiddos who have emotion regulation challenges, it might feel like you have a limited number of positive teacher-child interactions with them. It might feel like you're constantly having these interactions that maybe aren't as positive as we would like them to be. And we know that that's a real thing and we know that that can also lead to challenges for kids later on. So thinking about what are some of the ways that we can support kids' emotion regulation throughout the day is this something that we'll, again, keep touching on throughout our time together this afternoon.

So again here-now, remember-I'm not going to go through these again-remember, this is our general process for how we learned to regulate. So now we're going to look at Recommendation 2 from the practice guide, along with some suggested strategies for how we can think about emotion regulation for these kiddos. So as a reminder, Recommendation 2 is where we're going to talk about how we can modify the classroom learning environment to support these kids with our emotion regulation challenges.

So I want to point out something. You probably notice on the bottom of your screen here, you see these boxes that talk about the different levels of evidence? The way these reports were developed-and there are a series of practice guides-they convened a panel of experts in their respective fields.

So in this case, a panel of experts on social emotional development and challenging behaviors. And they reviewed many, many studies and looked at, what are these interventions studies? What are some of the things that teachers or researchers or whoever may be leading the study or participating in the study, what are some of the things that they do to help modify the classroom learning environment to support or decrease challenging behaviors? And from that, they looked at all of these different components and they looked at the level of evidence as well. So we know from the work that this panel did that modifying the classroom learning environment is one of the ways we can help support children's emotion regulation. And doing so has actually strong evidence. So we know that there's a lot of support that when you try some of these things and modify the environment, that that can really make a big difference for kids.

So why does it matter? Well, we know that learning environments include triggers that lead to challenging behaviors. Right? This is no shock to you all. Even some of you have mentioned changes in routines can sometimes be enough to set kids off and maybe have a meltdown and make things challenging for them. So these triggers can be anything from the physical set up of the classroom, the materials, as you all mentioned, routines or schedules. Maybe even the structure of some of the learning activities. Or for some kids, just maybe a lack of understanding of the classroom expectations, or a lack of an ability to know what to do to meet the expectations, or what are the acceptable things that I can do. So altering our environment 
to eliminate or, perhaps more realistically, mitigate these triggers can help reduce the occurrence of these inappropriate behaviors.

And again, we are realists. We know that it's not always possible to eliminate the environmental triggers, but we also know there are likely some processes or supports that we can get creative with that might help kids respond to these triggers differently, or some things we can-tools we can give them to know what to do when they are upset.

Alright. So putting it into practice. So now we're actually going to review each of these ideas you see here on your screen. So we'll talk about classroom expectations, modifying the environment, and then we'll also look briefly at some adapting or varying the instructional strategies to increase academic engagement in the classroom.

Alright. So first and foremost - so the classroom behavior expectations. So this is nothing new to you all, but I think it's good timing. We're coming up or maybe have just started a new school year, for those of you that aren't year round. We know that teaching and practicing behavioral expectations or rules throughout the year is really important for all kids-whether that's the youngest kids, or if you're maybe slightly older grades on the early childhood continuum. So maybe if you're in first, second, or third grade, we know it's important for all kids. So the way we practice these-we want to make sure we're using explicit teaching strategies, modeling, and just having these positive relationships to reinforce our expectations for kids. So this not only includes just general classroom rules and expectations, but we also want to think about rules and expectations that might be a little different for different parts of the day.

So maybe you have a set of rules or expectations for when kids arrive and leave the classroom, or for older kids, maybe how they turn in their assignments or what the expectations are there. Some teachers even have certain ways that they want to just ask the teacher for help. So maybe if the teacher is wearing a certain - I had a teacher who would wear a certain hat, and that was her cue to kids that I'm busy helping other kids in the classroom, so you need to find a different adult. So understanding what some of those rules or expectations may be. Transitions are a huge one. So we want to make sure kids understand the rules around transitions in the classroom. And when we have changes in routines or schedules, what are our expectations? What are we going to be doing a little differently? So lots of different times. So it's not just these general rules, but it's also you want it to be context specific as well. So within this time when we're getting ready to go outside and we're coming back inside? What are our rules? What are we going to do when we get back inside? Those are all things that we want to be practicing in modeling with kids as much as possible.

So we know that for kids in the primary grades, we recommend that teachers consider practicing these behavioral expectations daily for the first few weeks of school, and then maybe even reserving a little bit of time, maybe 10 minutes here or there, or even a few minutes here and there, where they can't practice those rules or revisit them weekly, or as often as needed. 
So for younger elementary students, so maybe just a little bit older, we know that these kiddos can also benefit from constant visual reminders. And we know those are also helpful for our youngest learners as well, and we'll look at some examples in a few minutes. But constant visual reminders and practicing is helpful for them as well. And then for older students, you know, they're still going to need reminders about behavior expectations, especially if they come back after vacations or holiday breaks or things like that. You'll want to make sure you revisit those rules. So, if you're in school now, maybe getting ready to have your three-day weekend, you might want to reserve a few minutes of your time Tuesday morning to go ahead and review those expectations again just to remind kiddos of what those are.

So why is this important? Right, I think this is pretty obvious. And you all have experienced this firsthand. But we know that this is important to review these, because sometimes it might be the case that, despite the fact you've reviewed them a million times, or what feels like a million times, it may be the case that some kids just can't remember all of them. I've been in some classrooms where there are so many rules that kids just-it's a working memory issue. Kids just can't remember eight or nine rules. So maybe think about what are some ways I can change these up a bit to help kids remember them? Or you might have kids who remember the rules, but they don't remember, I know this is a rule. I'm not supposed to do this. But I don't remember what I'm supposed to do instead. So we'll look at some ways in a moment here that we can think about those things perhaps a little differently.

Alright, I hope you're hanging in there with me. I love having all of you on the webinar. It looks like we have about 75 people, but I hate that I can't see you. So, I hope you're hanging in there with me.

But now moving on to classroom expectations. So here are some considerations if you're not already doing these things. Some considerations when setting up the classroom expectations or rules. So we recommend keeping the number of rules you have to less than five. And in fact, if you're in a preschool or pre-K setting, you might want to start with just three rules at the beginning of the year.

So remember we talked a little bit earlier about working memory, this cognitive regulation. And working memory is a piece of that. Right, so we know that for little kids, they can only hold a certain number of things in their little memories and minds at one time before it starts getting a little hectic for them.

So think about even in our hearts and flowers tests that you took. It was pretty easy when I had-do you remember one rule was really easy. Two rules, right? Remember, what did I do for hearts? What did I do for flowers? But it was pretty easy because I mean, you were only seeing flowers on the second time. 
But then when I asked you to keep multiple rules in mind that may also be conflicting with what your initial reactions are, your gut reactions maybe, it became really challenging. So again, that's us as adults.

So asking our youngest kiddos from the get-go to retain four or five, six, seven rules might be a little much and a lot on their working memory, a lot for them to retain. So want to keep it fewer, and then you can always, always add more as the year goes on. Once kids get a good handle of the initial really important ones, you can add some more here and there if you want.

And some ways I've had teachers do this that I think has been really helpful-so in one of the, Connect for Learning Curriculum, that we do a lot of work with, we've had some teachers where they have three behavior expectations. And what's interesting is they do them at a much higher level. So they might - what I mean by that, for example, some of the behavior expectations are things like, be safe, be a team player, and be respectful. So those are the three main rules that kids remember, but then they also have a lot of conversations - what does it mean to be safe? Well, that means things like walking feet, gentle touches, no throwing things. But kids are able to remember, be safe. Then they learn this larger concept of what does it mean to be safe? And it might feel like a lot, but I have to say from experience that kids really can learn those things. And it's really interesting to see them put that into practice. Or be respectful. So that might be things - if you want kids to raise their hands during certain times of the day before they ask a question, or ask their friend before they take a toy. These are all things that can come into play there. And even interesting, be a team player, I've seen them put more specific discussions around things like making sure my friends aren't lonely. So things around being a good friend. So if you see a friend alone, ask them if they want to play or they want to talk or anything like that. So just some things to consider. Don't have to do this, but some things I've seen in practice that have worked pretty well.

Interesting. Tell children what to do. So I think you all are probably doing this, but a reminder never hurts. We want to make sure our rules or expectations are worded in the positive. So we want to tell kids what to do. So we don't want to have it full of don't run, don't hit, don't do this, don't do that. We want to put it in the positive.

So you see the example here on the screen. So listen when your teacher is talking, as opposed to don't talk when others are talking. Follow directions quickly. Respect others. Respect yourself. Respect your school. So again, want to word those in the positive. And a fun book that we look at, and we'll do some things with kiddos with is, "No, David." I can't remember the author. I apologize. I'm blanking on that. But that's a little book for those of you that maybe aren't familiar with it. Very easy, very short. We use it a lot for preschool and pre-K. And it's just a series of images in very short words here-short stories, sort of thing-where this little boy is just-everything he does is just not appropriate. And all he hears is, "no, no, no, no, no." So we do a little activity with teachers actually. It might be fun. But we also do it with kids. What are some things we could tell David to do instead? We don't want him to climb on the chair. But 
what should we tell him instead? Or what can he do? He's not allowed to climb-once the cookies are on the top shelf, but he's not allowed to climb on the chair, what could he do to get those cookies? So having kids' brainstorm. Maybe he asks his mom or he asks the teacher orit's really interesting to get kids thinking about that. It kind of takes it off of them and it's all about David. What could we tell David to do instead. Oh perfect. David-our David on the webinar-found this for us. It's called No, David. And the book is by David Shannon.

So there you go. Thank you. I appreciate that, David. Thank you for answering that question for us.

Alright. Also you want the rules obviously to apply to all children. So we don't want to make these larger classroom rules. That aren't expected to apply to everyone. And then really important, especially for our youngest learners, but also for those of you that may be even in kindergarten, first, second grade-include some of those visual icons. We know for our youngest learners, kids who can't read yet, those visuals can help them remember the rules. But what's really important is we also know for kids that might have-might be identified with special needs, or children who are perhaps dual language learners, we know that these icons can be really helpful in allowing them to remember those rules or expectations as well.

Alright. So we know next year that maintaining the instructional momentum of the classroom can be really challenging when behavior problems become persistent in the classroom. So whether that's one kid, or if you have a few kids that are having these issues. But we know that it's important that we identify these challenges and modify the environment as much as we can to address these triggers. So this might be things like the physical environment, the schedule, transitions, lesson pacing or duration, different teaching strategies we use, and allowing kids choices, when it's appropriate.

So let's look at a few of these in a little more detail. So first, thinking about the physical environment. So we want to make sure we have a smooth rhythm and traffic flow that avoids areas getting congested or being unsupervised, if at all possible. And some ways we can do this are to perhaps implement a center management system to help kids navigate centers. So for preschool and primary classrooms, this might be-the teachers might need to define the appointed activity spaces in the classroom. So let kids know where is it appropriate to do this type of activity. We'll look in a moment at ways we can do that. You can also, you also want to think about, are there center management systems in place that allow kids or help kids know what they can do or where they can go during center time? That's a really big one that can lead to some confusion and perhaps meltdowns if not addressed, early on. And also things you see, you know, things, as you see, are just making sure kids know where stuff goes in the classroom is really, really helpful as well.

So looking at defining the space in the center management piece here. If you're not already doing this, we know that center signs, whether they're teacher or child made, should be visible 
to kids so they know what the different areas are. Color coding is really helpful to help visually separate centers. Again, especially if you are with the youngest learners or kiddos with special needs or who may have some other challenges, color learning can be a really effective way to help kids know what centers they're supposed to be in, especially when combined with another method that we'll look at on our next slide here. Or other methods. So maybe it's strategically arranging your furniture. I've seen some teachers that will put tape on the floor-if you're allowed to do that. I know some places are not. But l've seen teachers that have done some of that as well.

So limiting the number of children in a center can be helpful in helping to reduce these challenging behaviors. And again, we recommend using visuals so that kids can help do this as well. So we don't just want to say, "oh, only for friends in the center" - without putting a visual up to help kids remember that. And what's really nice is when you have these visuals up, if they're arranged just so, kids can kind of be self-correcting in a way, where it doesn't have to always be an adult sitting near the child reminding them what to do or that the center is full. So for example, you see this first picture here. This is kind of a self-correcting-in the block center, you can see four friends are allowed in the block center at one time. So you can see the empty space down at the bottom. There are four squares there were kids put their pictures to show when they're going to be in that center. So once that fourth block gets full down at the bottom, that means no one else can go in that center yet. So just some fun ways.

I've had teachers that will maybe just do children's names or they'll do pictures with names to get some of that name recognition in yet one more context, which is always a good idea and helpful.

This middle picture is interesting. So you see here-this was in a classroom where the centers were color coded, as you can see the different colors. And the teacher had clothespins. Now, I know some places don't want to use clothespins because they can pinch hard, but whatever method you may come up with, or be allowed to use. This teacher color coded clothespins and similarly, once all the-for example, all the red clothespins were gone, that meant that center was full. So kids had to pick somewhere else to go. What I really like about this is that kids would put the clothespins on their shirt or their shorts or pants or whatever so that they would wear it. And it was really interesting, because remember, we talked about how kids develop emotion regulation or develop self-regulation? What's interesting is when kids have something that's wearable, and often the color coding is a nice way to do this, so if I know I'm going to the red center today, I put my red clothespin or my red clip on. What's interesting is you'll see some kids, once they learn the rules, they'll start other regulating.

So I've been in classrooms-I'll give you a personal example where I was in a classroom and they had this sort of management system you see here in this middle picture. And I was in the classroom and I wanted to go into a center and take some pictures of some of the cool things the kids were doing, but I didn't have a clip on. So when I got to the edge of the center, this 
little preschooler came out and we'll say, greeted me at the edge of the center, and would not let me in the center because I didn't have the right color clip on. In fact, I had no clip on. You know, and she just said, you know, "This is the red center or whatever color it was. You can't come in here because you don't have to red clip." And she was very polite about it, but you know, I couldn't really argue with her because that was the rule and I was breaking the rule. So needless to say, I did not get in the center that day to get pictures, but you'll be proud to know that I did kind of outsmart this little four-year-old the next time I was in the classroom. And the teacher that actually made some for herself as well, we made rainbow clips. So the adults in the classroom had a little clip that had all of the center colors on it. And they would wear it during center time and that was kind of their all access pass that would allow them to go into any center, because they had a clip with every color. So something to think about if you're modeling this color system where kids have something wearable that allows them to do this other regulation, because they start looking to make sure that other people in this center have the right color clip on for that center. So if you're doing that, take my lesson learned and make yourself a rainbow clip as well so that you don't get denied access to a center, because you can't really argue, because she was following the rules and I was not. So I really had no ground to stand on there at that moment in time.

And then finally, you see in this third example just another way that you can perhaps help limit the number of players or rotate kids. So this computer turns-it's a nice one you see as kids move up. So I'm playing. So we see in this example, Rebecca is at the computer. When Rebecca's time is up, she'll take her name down and then the child in spot number one, the way in spot number one, will move her name up and it'll her turn.

Many options for this. Now what I also love, love, love-and I've seen this work in so many different ways - and I think it's something that we don't - I know I didn't always think about, but once kids get to their centers or whatever activity it is they're doing, we want to give them choices once they get there. So you see activity choices are important. So you see here in this center, these are the different options.

These are the different things that are appropriate for kids to play or do in this center. So again, those visual icons are really nice there as well. And then what's - if you want to take it even a step further, you can say, "Here are the appropriate activity choices in this center, and then you can even make some of these visuals you see on the right hand side of the screen here, here are some of the steps. Here are some of the things-or here are the things that you do in this activity." So you can outline the steps visually for kids as well to remind them what are the steps to the activity. That's great. I'm allowed to color or make a card, but what are the steps for that? What do I do when I'm done with my materials? And you can outline that for kids. So it's really a nice way-as you know, you have to teach kids what these mean. You can't just put them up, otherwise they're just going to be wallpaper that you spend a whole lot of time making. But these can be really nice ways to help young kids as well, and maybe kids with 
behavior regulation challenges to remember what are the acceptable things that I'm allowed to do. So these are really, really helpful in that sense.

So of you might be wondering, this is great or I'm already doing this or l'd like to be doing some of this, but how can we get regular education teachers and administration on board with supporting all students with these accommodations and modifications. So good question. It looks like Tanika just posed that question for us in the Q\&A box. So thanks for asking that, Tanika.

So you know, and I think I don't have an exact answer for you unfortunately, but what we've done-in my experience-you know, we've been in classrooms or we just-it's just kind of set up the expectation from the beginning. This is just how our classroom functions. When we set up our classroom at the beginning of the year, we color code centers. That's just what we do. It's not introduced. We're not doing it just for Jeremy because he has a hard time remembering where to go. This is the way-this is our classroom. This is the way we're setting it up. And I think if it's set up that way, and again, this might-I think it's good timing with it being close to the beginning of the year. This might be an opportunity where you all can just set these as general classroom set ups or expectations. That way it doesn't feel like they're coming in later to just be something special or some special rule for one kiddo. But this is the way we all do things. And that's really been the way where I've seen it most successful in my experience working with different sites, is when it is set up that way kind of from the get-go, that this is what we're all doing. Or if you're already in the middle your session, it's just the expectation, this is what we're all doing. It's not, again, this is what Jeremy is doing because he has trouble following directions when we go to center time. This is what we're all going to do to help us all remember the rules or remember where we're allowed to go in centers, or what activities we're allowed to do in the block center and what the steps are to those activities.

So I'm hoping, Tanika, that maybe helped to answer your question a little bit.

Alright. So looking here. Schedules and routines. I can't remember your name. I apologize. Someone mentioned earlier when we were talking about challenging behaviors that sometimes you have those kiddos, when there's a change in the schedule or routine, they just have a bit of a meltdown. And we know that's the case. But again, we also are realistic and we know, this is what's going to happen. We can't get around it. So schedules and routines. We want them to be visual. And as you see here, you can have, on the right-hand side, visuals to help kids remember the routines as well. So it's not just first we go to meet and greet, then we wash our hands, then we do breakfast, then we brush our teeth. But it can be, as we saw on the previous slide, within the listening center. Here are the routines. Here are the different steps for the things we do in the center or within this activity.

So what I think is really helpful in the scheduling is thinking about when you do have these changes in routines, thinking of a way to mark those for kids. So we want to think about, when 
we have a change in routine, I've seen some teachers that might put a red " $x$ " or put an exclamation mark or something else on their visual schedule that they visit multiple times throughout the day so that at the very beginning of the day, you want to point that out to kids. Draw their attention to that right away. So it might be, for example, oh my goodness, I was in a classroom where they weren't allowed to go outside to recess that day. They were in an elementary school and their elementary school students were doing some of their standardized testing. So they didn't want the preschoolers going out to the playground and being loud and kind of right next to the windows of the kids that were doing the testing. So the teacher put a giant red circle over their outside time and in the very beginning of the day when they reviewed their schedule, because they review it every single morning and then they review it multiple times throughout the day, she would remind them, you know, remember, we have this red circle. That means something's going to change here. So they would talk about why there was a change there. And then multiple times throughout the day before they got up to outside time, she would remind them, now remember, when get to what should be our outside time or recess time, we're going to go to the gym to play instead because our friends, who happen to be their book buddies, are doing some tests today. So just thinking of a way to visually mark that on your calendar, your visual calendar-or visual schedule, excuse me, can be a really powerful way to help mitigate some of those meltdowns that may happen with those changes in routines.

So transitions. I'm not going to spend a lot of time here because you all know from experience these can be challenging. So managing these transitions quickly and efficiently is key. So just as we want to remind kids that changes in schedules are coming up, we want to remind them when a transition is coming up. So that can be done by reviewing the schedule multiple times throughout the day so that they know as soon as we get done with outside, we're going to come and have circle time and we're going to do our-another reading activity for the day, for example.

This is really key. I know you all know this, but we want to make sure we provide clear and succinct directions ahead of time for kiddos. So we want them to know ahead of time, great, we're outside. When we get back in, what are we going to do as soon as we get back in? We're going to go to the rug. What are we going to do when we get to the rug? You know, here is the two acceptable things you can do when you get to the rug before we get started on our next activities.

Then obviously you want to have your materials out and ready for the next activity. And as much as you can, begin that next thing immediately or have one of the adults in the classroom begin that immediately. And then of course, just make it fun. We want it to be fun.

Alight. So teaching strategies. This is, again, things that I know as professionals you all think about these things. But we want to make sure that the strategy you pick is appropriate for the lesson type, the kids in your classroom, and the time of day. So you want to think strategically 
about when you have your whole rooms or small groups or center times and arrange your schedule so that kids have a little bit of variety throughout the day.

And the same here with our instructional strategies. We know that when there's a mismatch between kids' ability level and the difficulty or length of a task that inappropriate behavior is more likely to occur. So we want to think about having strategic and targeted questions during activities, keeping the activities kind of moving along at a good pace, varying the materials and the assessment strategies that we use with kids.

And then don't be afraid - this is really important here and I think one that we often - I know I over-looked as well myself, don't be afraid to engage kids in peer tutoring and learning. Pair kids up. If you know that Mark is really good at building in the blocks and thinking of new ways to play in the block center, pair him up with someone that maybe gets to the block center and just doesn't know what to do other than build towers and knock them over. You know we all have those kids where they build a tower, knock it down, build another tower, knock it down. And some kids can do that for a full hour. But maybe pair Mark with them. You know, if Mark is really good and strategic about building different things, pair those kiddos up and let them do some of that peer tutoring and learning to support those different skills.

So this is really interesting. Right. So we want to make sure we're asking strategic questions to kids - to not only determine their level of understanding, but to also increase their engagement throughout the task. So this is directly from the practice guide. So I definitely recommend that you read this in more detail. They give a lot more detail than we have time to go over today. But we know from research that when kids are learning new tasks, we want to ask or elicit four to six responses per minute from students during these tasks where we're presenting new material. Now what's interesting is you also want to throw in some easier questions in there. We don't them to all be questions that the kids struggle with and maybe can't answer, because we know we're asking kids - when they're able to get about 80 percent of the questions we're asking them correct, it helps keep them engaged as they're learning new tasks.

And then similarly when we're looking at practice tasks, so doing tasks that are letting kids practice skills that they've already learned or have already been exposed to, we want to ask questions that elicit responses from them 8 - 12 times per minute with a target rate of 90 percent accuracy. And that's not saying we don't want to challenge kids, but we also want to make sure we're asking questions that kids might know the answer to so it helps keep them engaged and help them realize, I do know some of this. I can do this. I got it.

So I want to take just one minute here and reflect on the strategies we just discussed. And I want you to think of one concrete step, based on these strategies that you might use to help support positive behavior in your classroom, or setting. So we'll take just one minute and then we'll come back together and we're going to get into Recommendation 3 and watch some videos of some fun stuff in action. 
Alright. So if you have any of those, if you want to just type those in that Q\&A box for us, or if you just have them in your head and are thinking of ways that things that you might care for that we've talked about already, that's fantastic. Oh, great. So we have Marta, who talked about photos in group limits. Thank you for sharing. Excellent. Yeah, so keep adding those to this Q\&A box, because we've love to see some of your ideas and I'm sure your colleagues would as well. So keep those coming.

In the meantime, we're going to keep moving forward here. We're going to look quickly at our overview of Recommendation 3. So this is where we get into the good stuff. So teaching and reinforcing new skills to increase appropriate behavior. So we know that there's strong evidence for this. We know that kids can learn to control their behaviors and emotions. And what's really cool is that we know-so sometimes we want to take advantage of those teachable moments, but sometimes we just need to take a moment and have some activities that explicitly teach kids strategies that they can use to control their behaviors or emotions.

So we're going to look at a few examples of those in just a moment.

But putting it into practice, we're going to look at important things. So you want to identify where they need explicit instruction so we know what activities to do. Two, we'll actually teach some of these skills through practice and feedback. And then very, very briefly, we'll look at providing resources for appropriate behavior.

So identifying the needs for explicit instructions. So we know that it's really important to first determine whether the kid simply doesn't know the behavioral expectations - do they not know the rules or what's expected of them? Or is it that they know the rules and they can recite them by heart, but they just don't have the necessary skills to carry out the desired behavior? We know those are very different things, so before we assume a kid is knowingly misbehaving, we want to make sure-do they actually know the rules? Do they really get them? Sure maybe they can recite them from heart if they're part of a song or something like that, but do they really understand what those rules are? So you want to take some time to think about those and identify our areas of need.

For all the kiddos we want to think about are there any instances where they can perform the behavioral tasks successfully, where they're successful at that? And if so, what are those scenarios? Or maybe it's that Suretta is really great about following the rules in one situation, but when we really observe her, we realize she's great at following this rule in center time, but when we get to small group, it maybe falls apart a little bit. So let's think about why might that be.

Similarly, do they know when and where the behavior is appropriate? And then for older kids, those of your who have older classrooms, you might also want to think about implementing a 
self-monitoring system that allows kids to kind of self-monitor their behavior so they can keep track of when they're doing some of these things. So perhaps a little checklist that you create for them and help them reflect on after a task or during a task.

Again, a lot more information on both of these in that practice guide, so I definitely recommend that you check that out, especially if you have the older kids and want to do this self-monitoring system, there are some really great pointers in that document that can help you with that.

So teaching skills, the fun part here. So we want to help kids gain the needed skills by giving them instruction. So let's look at some different things here. So we know explaining and (re)explaining the behavior is helpful. Breaking those behaviors into concrete steps. Modeling and providing lots of examples. If you don't feel like you're going a little crazy by the number of times that you're going over a rule or providing examples, you might not be doing it enough. Create opportunities for practice. Prompt and cue often, especially a first. Give kids those prompts or cues to remind them what the rules are, whether those are visuals - And I love the idea that someone had here about maybe taking photos. Maybe you can take photos of your kids modeling the rules or the expectations or modeling the steps to the activity, for examplewhich, again, can be helpful for all of our kiddos. Younger kiddos. Can be helpful for kids with special needs. Can be helpful for kids who might be ELLs (English Language Learners) or DLLs (Dual Language Learners). So very helpful things there. And then we want to give specific feedback and praise as well.

Alright. So now moving on to my favorite stuff here. We're gonna look at a couple of activities. So these activities we're going to look at are based on the pyramid model. And I'm sure a lot of you have seen or are familiar with the pyramid model. And this comes out of the Center on the Social and Emotional Foundation for Early Learning, or CSEFEL. And if you go to the chat box, David just posted the link to this group's materials here. It's a group out of Vanderbilt. So you will want to visit that chat box, or you can jot down C-S-E-F-E-L. And if you Google that, you'll get their link as well. So that can be another helpful way to get to that. So this group has more strategy than you could ever want for a variety of age groups for ways to help with challenging behaviors. This is kind of the-this is what they do. This is their bread and butter. And one of my favorites is The Turtle Technique. So someone had mentioned where kids just don't - they get in their own head and they don't stop and think. They just instantly react. And this turtle technique is an example of a strategy you can use to help kids stop, think about the appropriate options for a response, which is a separate activity. You have to teach them what are some of those appropriate options or ways to respond. And it just gives them a chance to help calm themselves and think about appropriate solutions.

So here are The Tucker Turtle Steps-so recognizing that you feel angry and upset. So you all had mentioned that. Maybe not understanding the emotions or the feelings, but helping them recognize, what does it feel like or look like when you're angry or upset? You stop and you think. In Step 3, you go into your shell. You take three deep breaths, or more, right? Maybe if 
it's a challenge situation, maybe you take five. And you think calm, happy thoughts. Coping thoughts, but we don't use that word with kiddos, but think about calm happy thoughts. And then you come out of your shell when you're calm and you think of a solution.

So we're just going to watch a little snippet of this video. And these materials, including this video, are all available at that site that David has posted in the chat box for you. So I recommend you go there and you can get these resources yourself as well and read more about them. Let's see.

Let me apologize there. My video is not cooperating. Let's see. Why am I not getting our play option? There we go.

[VIDEO PLAYBACK]

TEACHER: Tucker Turtle takes time to tuck and think. Tucker Turtle is a terrific turtle. He likes to play with his friends at Wet Lake School. Have a seat.

STUDENT 1: Wet Lake School?

TEACHER: Have a seat. Who's his friends? Tell me who his friends are?

ALL STUDENTS (Cross-talk): Duck. Alligator.

TEACHER: And who is this?

ALL STUDENTS: The owl.

TEACHER: The owl. You are right. But sometimes things happen that can make Tucker really mad. Can you show me a mad face?

ALL STUDENTS: [GROWLING]

OFF SCREEN VOICE: Oh, goodness.

TEACHER: When Tacker got mad, he used to hit and kick or yell at his friends. His friends would get mad or upset when he would hit, kick, or yell at them. How would that make you feel?

ALL STUDENTS: Sad.

TEACHER: Would that make you sad? That would make me sad, too. Tucker now knows a new way to think like a turtle. When he gets mad-

STUDENT 2: I'm happy.

TEACHER: We're going to stop. Show me stop. Stop. Pull in your shell. And then count.

TEACHER and STUDENTS: One, two, three. Take a deep breath.

STUDENT 3: I'm out of my shell.

TEACHER: And then-

STUDENT 4: Can I tell you something, Ms. Christy?

TEACHER: Mm-hm.

STUDENT 4: He can't come out.

TEACHER: Brandon's is, look. Brandon's is coming out. And what is your turtle going to do, Brandon? 
STUDENT 3: He could think of a good problem.

TEACHER: He's going to think of a good way. Good job, Brandon. You remember to think like a turtle.

STUDENT 4: Me too!

TEACHER: You too. Yes, you did.

STUDENT 2: Me too!

TEACHER: You too.

[END PLAYBACK]

CRYSTAL DAY-HESS: Okay, so that is an example of a teacher introducing Tucker the Turtle. So again, if you go to this website, again, in your chat box, highly encourage you to visit your chat box there before you leave today and copy that website down. You can get this video and you can actually get the book that the teacher was reading there at the beginning, "Tucker Takes Time to Tuck and Think" is the name of that book. So you see, it's a really interesting way to teach kids how to not just initially react, but to think it about, when I am getting upset or angry, this is my new thing. This is my new normal. This is what I do first. I stop and take a moment. I think, tuck into my shell. I take deep breaths. I think of a solution, then I come out of my shell and put my solution into practice. So that becomes the new normal as opposed to, l'm angry. I'm going to pick up the first thing near me and throw it across the room.

So it takes time. It's not a magic thing that's going to work instantly, but I highly recommend it. I've seen this method work with a lot of kids, both kids that just have kind of what you might call typical levels of challenging behaviors and kids that also might be on the higher end of those as well.

So the other really cool, practical activity that, again, you can also get this CSEFEL website is this solution kit, sometimes referred to as a solution suitcase in the Connect for Learning Curriculum. So this solution kit is really interesting. You see these 10 solutions here. So there are activities that you can do with kiddos that go over each of these solutions and give examples and ways you can talk about these kids. But you present these as ways. Kids can actually put these on a card or put them on a folder or something like that. And these are thethey're kind of go to when they're having a challenging situation with their friends or with their peers, these are the acceptable solutions that we're going to give them to try when not having a hard time with their friends. So you see things here-get a teacher, ask nicely, maybe you just ignore-I think that's a really important one. I think even as adults; we sometimes forget that that's an appropriate solution is to just ignore it. That sometimes might be the best solution. Saying, "Please." Playing together. Saying, "Please stop." I think that's also important. Sharing. Trading. Waiting and take turns or getting a timer. So these are all the things that are-these are the appropriate solutions for kiddos when they're having disagreements, let's say, with their peers. 
So we're going to watch this little video. So I apologize. The quality is little grainy, but this again, is from that same website. So these are kiddos, as you can see, playing with a train in the block center. And you'll see what happens here. As we're watching this, think about what's happening here and when might be an appropriate time for the teacher to talk about some of these skills with kiddos.

[VIDEO PLAYBACK]

STUDENT 1: Oh. Can I play with your train?

STUDENT : No. You play with your car.

STUDENT 1: No, I need a car. I use a train.

TEACHER: What's going on guys.

STUDENT 1: Use a train.

TEACHER: Well, you know what?

STUDENT 1: I want to use it.

TEACHER: Let's see. No, let's think about some things you can-we can work this out.

STUDENT 1: He don't want train.

TEACHER: Alright. Let's think about some ways we can do this, OK? Alright, Cameron. Are you ready? Let's go. Darren-wait, wait, wait. Let's look. I got some pictures here. Alright. And so Cameron, why don't you come over and play with your train? So could you guys share it?

STUDENT 1: No. He don't want to play with my-he don't want to play with a train.

TEACHER: Are you ready to share? Or you could-

STUDENT 2: Trade?

TEACHER: Trade. You want to trade your car for the train? What do you think about that?

STUDENT 1: I don't want no car.

TEACHER: I could help-he says he doesn't want a car. Hm. Do you think you could play with the other train?

STUDENT 1: No.

TEACHER: No? But you what, Cameron?

STUDENT 2: Yes?

TEACHER: Is it OK sometimes if our friends aren't ready to play together and share?

STUDENT 2: Yes.

TEACHER: Maybe we could wait for a little while? Huh? And then we can come back and ask them, so if we decide to do that, we can wait-Cameron, look. We can wait and take turns, OK? Can we do that?

STUDENT 1: Yes.

TEACHER: Yeah? Oh, he agrees. You know what? What do you think?

[END PLAYBACK] 


\section{REL \\ C E N T R A L \\ Regional Educational Laboratory
of Marzono Research}

CRYSTAL DAY-HESS: [LAUGHTER] Alright. So you see this is a good example. This teacher, she had them write the different solutions and she was going through them with the kids, helping kids think through. So I think his name was James, the little guy in the red. He didn't want to share. He didn't want to trade. And I think what's interesting is the teacher gives kid's room to say, "No." It doesn't have to be the first solution a teacher offers that the child is forced to say, "Yes, this is what I definitely want to do." So I think it's interesting how she models going through, when you want to trade and your friend says, "No," what do we do next? Well, now we can go to some of our other solutions and see if another solution might be appropriate or might work. And then finally he agreed to wait, so you saw her a little bit of shock in her face, which I kind of loved. Like oh, he agreed to wait and take turns. Alright. Let's do that.

So this is what he did-recommend, please.

And it looks like Alicia just posted that link for us, another link to the pyramid model. So thank you for sharing that with all of us up there in that Q\&A box as well. So I highly encourage you. This solution kit is revolutionary.

Let's just say every classroom I ever go into now, I may or may not have a copy printed in some of my materials that I take with me all the time and encourage everyone to use it. And I even know some adults that I think - I kind of want to hand them a copy of this solution kit. But you know, something to think about. There's something for everyone in the solution kit.

So think about this. Think about this example. I'm getting ready to read to you in just a minute-I know we only have about seven or eight minutes left here, but think about this example. Anna in the science center using the balance to explore the weights of a block and a toy train. Oscar comes into the center and takes the train from the scale because he needs it to run on the track he just finished building in the block center. Anna gets upset. She yells at Oscar and pitches him in the arm. And then Oscar starts crying.

\section{So think about that.}

Now let's think here. What might you say to Oscar and Anna, or what skill might you try to teach Oscar and Anna-so think about it, what might you try to teach them? And even more importantly, when might be or what might've been the ideal time to have this conversation with them and teach this new skill? So take a minute. Talk if you're watching this webinar. Talk. Think if you're by yourself. Post some of your ideas in that Q\&A box. That'd be fantastic. So think about in that situation, when might be the ideal time to teach them a new skill or to teach them how to react in that situation?

Alright. So the top of our curve here, this very top arrow in the center of your screen, that represents the moment when Oscar starts crying. So is that our best time? Probably not. we probably don't want to wait to introduce a new skill or to try to teach a new concept or, in our example of teaching Tucker the Turtle, or teaching a solution kit, you don't want to make your 
first introduction of those things in a crisis moment. We don't want it happening at red arrow, the peak of when things are getting real and people are getting upset and getting frustrated. Right now, sometimes that might be your teachable moment. You're like, oh my gosh, we haven't taught the solution kit yet? Probably don't want to teach something as complex as a solution kit in a moment like that. But you're going to have to-there might be times where you have to do some of those things.

But then if we look down here at the bottom of the blue arrows - so this might be the point in time before the scenario even begins. So this might be for us when Oscar was in the block center and Anna was in the science center and they were doing their own thing. You don't know what situation's going to come up yet. So it might not make sense, or you might not even know what new skill or activity you want to focus on with kids. Jumping ahead a little bit, that yellow arrow is the point in which the situation starts to escalate a little bit. So that's when Oscar first takes the train from Anna.

And really our ideal time is this green arrow. So this, in our scenario here with Oscar and Anna, represents the point in time where it's just beginning. So this represents the point in time when Oscar first comes over to the center with Anna. So this might be the time where you want to jump in, if at all possible. So again, thinking about, Alright, we know that these moments happen and you have to address them in the moment as they come up, but we also want to recognize that if you're going to do things like The Tucker the Turtle or the solution kit, that you want to first introduce those and have a lot of your conversations about them when things are-when everyone's in a good state, so to speak. When everyone's calm and we're not in the middle of a crisis moment.

And then wrapping up in our last few minutes here, just a little reminder about reinforcers and consequences. You want to manage your consequences so that the reinforcers are provided for appropriate behavior and withheld for inappropriate behavior. So with our positive reinforcers, these are things that you want to add for kids when things are going well. So when you want to increase the frequency of recognition of reinforcement for appropriate behavior. So when kids are doing things well, especially those kiddos that maybe it feels like you mostly have negative interactions with them because they're always demonstrating or frequently demonstrating these challenging behaviors - when they're doing something appropriate, really give them those reinforcers and that recognition.

And then on the converse, on the flip side of that, when kids are demonstrating inappropriate behaviors, you want to withhold or prevent access to reinforcing consequences. So what that means is when a kid is doing something that they're not supposed to be doing, as much as you can-you may not want to draw attention to that misbehavior, but try to make those problem behaviors ineffective for the student by withholding or preventing access to reinforcing things. So you know, maybe if they're doing something wrong, they aren't going to get their favorite toy that they were wanting in that exact moment. Or rather than saying, you know, "Karl, stop 
talking to Stella unless you're talking about today assignment-besides, you're only supposed to be talking if you finish all of your work." Maybe you could say, "Karl, complete your work and then you're free to talk quietly with your neighbor."

So giving them some examples and some things that they can get or can do if they're following the rules. So again, highly encourage you to visit that practice site. Lots of really great examples and things in there as well around reinforcers and consequences, which I know a lot of places and a lot of sites have their own systems in place for that. But some more information in the practice guide if you're interested. So l'm hoping, as we've been talking here, you've been thinking about ways that some of these strategies and practices can be put in place in your classroom or maybe ways that you're already using them and maybe tweak them a little bit. Or maybe they've just sparked some brand new ideas that maybe we didn't even talk about today. So yeah, I just want to leave you with this to help keep your sanity. As you're working with some of these kiddos, remember, we start with regulation by other. So adults regulating those kids. Then they finally get to that point where they can remember those rules a little bit and apply them to other people, so you might see a lot of tattling happening in this phase before they're finally able to move onto this self-regulation and really start applying those to themselves.

So in our last minute, if there are any closing questions that you all may have, please add those to that Q\&A box. Otherwise, I'm going to hand it over to our partner David at REL [Central] to wrap us up. But before we sign off, thank you everyone for staying with us and for all your time today. And I see we have some questions about whether the PowerPoint will be available. So, I will let David jump in now and answer those questions for you.

DAVID YANOSKI: Alright, Crystal. Thank you very much. We appreciate your insights and the concrete strategies you shared with us today. In answer to the question, is the PowerPoint available-it will be. We will make the slides and a recording of the webinar available. It'll take us about two weeks to get all the processing that we have to do to make it ready for the website.

But it will be available on the REL Central website. The easiest way to find the REL Central website will be to search REL Central. R-E-L Central. And then you'll be able to find it there on the IES website.

Again, thank you very much for sticking in with us today. And with that, I hope you have a wonderful rest of the day and a wonderful holiday weekend. Thank you and goodbye.

This agenda was prepared under Contract ED-IES-17-C-0005 by Regional Educational Laboratory Central, administered by Marzano Research. The content does not necessarily reflect the views or policies of IES or the U.S. Department of Education, nor does mention of trade names, commercial products, or organizations imply endorsement by the U.S. Government. 